\title{
Uluslararası Ticaret ve Elektronik Konişmentonun (BOLERO) Rolü
}

\section{International Trade and Role of Electronic Bill of Lading (BOLERO)}

Yurdagül Meral ${ }^{\mathrm{a}, *}$

a,Dr. Öğr. Üyesi, İstanbul Medipol Üniversitesi, IYYBF, Uluslararası Ticaret ve Finans Bölümü, Kavacık, Beykoz İstanbul/Türkiye. ORCID: 0000-0001-9244-1994

\section{MAKALE BİLGİSI}

Makale Geçmişi:

Başvuru tarihi: 31 Mayıs 2019

Düzeltme tarihi: 21 Ağustos 2019

Kabul tarihi: 02 Eylül 2019

\section{Anahtar Kelimeler:}

Avrupa Birliği

Elektronik Konişmento (BOLERO)

Uluslararas1 Ticaret

İthalat İhracat Yönetimi
ÖZ

Elektronik ticaret ve elektronik belgelerin artışıla, SWIFT ve Through Transport Club (TT Club) ortak girişimi ile elektronik koniş̧mento, BOLERO (Bill of Lading Electronic Registry Organisation) sistemi kurulmuştur. Bu çalışmanın amacı, 1994'de Avrupa Birliği tarafindan finanse edilen BOLERO projesinin, beklentilerin aksine yaygın kullanılmama nedenlerini tanımlamaktır. Literatür taraması sonucu, yaygın kullanımının önündeki engellerin başında bankacılık sektörünün teminat ve ödemelerde hala geleneksel orijinal kâğıt konişmento talep etmesi bulunmuştur. Ayrıca, elektronik konişmentoyu ilk kez tanımlayan uluslararası kurallar dizisi Rotterdam Kurallarının henüz yürürlüğe girmemiş olması, dolayısıyla ülkelerin yerel hukuki alt yapısının elektronik konişmentoya uygun olmamasının yanı sıra, BOLERO sisteminin, dışa kapalı, herkese açık bir sistem olmaması ve son olarak ise yüzlerce yıldır kullanılan orijinal kâğıt konişmento yerine elektronik konişmentonun, sektörün güvenini henüz kazanmaması olduğu görülmüştür.

\section{A B S T R A C T}

The electronic bill of lading (BOLERO-Bill of Lading Electronic Registry Organisation) has been established by SWIFT and Transition Transfer Club (TT Club). This study aims to explain BOLERO established in 1994 with European Union finance and reasons why it is not widely used. Literature review shows the reasons as banks requesting traditional, original paper bill of lading for collateral and for payments, Rotterdam Rules, first rules defining electronic bill of lading did not enter into force yet and local legal systems are not updated for electronic bill of lading. Other reasons are that BOLERO's being a closed membership system, not open to everybody and lastly having used original traditional paper bill of lading for centuries, the electronic bill of lading BOLERO is not found trustworthy by all parties yet.

\section{Giriş}

Uluslararası ticaret, sınır ötesi yani ülkeler arası mal ve hizmet ihracat ve ithalatını kapsamaktadır. Uluslararası ticaret hacmi, her geçen gün artarak, 2018'de toplam ihracat tutarı 19,2 trilyon dolara ulaşmıştır. Uluslararası ticarete konu olan malların bir ülkeden, diğer bir ülkeye taşınması, yani uluslararası nakliyatı kara, hava ve deniz yolu ile yapılmaktadır. Uluslararası taşımacılığın yaklaşık yüzde 84'ü ise deniz taşımacılığ 1 ile gerçekleştirilmektedir (Deniz Ticaret Odas1, 2017). Uluslararası ticaret ve uluslararas1 taşımacılığın ayrılmaz bir parçası ve en önemli belgesi olan konişmento, malların sahipliliğini gösteren, devir ve ciro yolu ile malların sahipliliğinin el değiştirmesini sağlayan kıymetli evraktır.

Genel olarak, bir konişmento, malların belirtilen şartlarda taşıyıcı tarafından alındığını kabul eder ve malların taşındığı şartları belirtir (Mo, 2003). Malların taşındığı geminin sahibi ile onları gemi sahibine teslim eden kişi arasında sonuçlanacak olan bir taşıma sözleşmesinin varlığını kanıtlamaktadır. Uluslararası ticarette, malların deniz

* Sorumlu yazar/Corresponding author e-posta: ymeral@medipol.edu.tr 
yoluyla taşınmasında en önemli belge olan deniz konişmentosu, uluslararası satış sözleşmelerinin finansmanını kolaylaştırmaktadır (Proctor, 1997, Bennet, 1914).

Konişmentolar geliştikçe, uluslararası ticaretin pratik ihtiyaçlarına cevap vermeye devam etmek için konişmento belgesi daha fazla bilgi içermeye başlamıştır (Wheble, 1975). Uluslararası ticaret arttıkça, çoğu durumda, kargo malları ile taşıyıcılar arasında, gemide tam olarak hangi malların teslim edildiğine ilişkin ihtilaflar doğmuştur (Astle, 1983). Tüccarların mallarını bir alıcıya göndermek istedikleri zaman aynı zamanda birden fazla konişmento kopyasını çıkarmanın gerekli olduğu ortaya çıkınca, taşıyıcı adına imzalanan konişmento kopyası en güvenilir belge olmuştur (Kozolchyk, 1992). Konişmentolar 14.yüzyılda, genellikle, sevk edilen malların cinsi ve miktarı ile alındıkları duruma ilişkin ifadeler içermektedir (Wilson, 2004).

Konişmentonun, uluslararası ticarette merkezi rolü oynamasına olanak tanıyan en önemli özelliği aynı zamanda mallar için bir sahiplilik belgesi olarak kullanılabilmesine olanak sağlamasıdır (Kindred, 1988). 18. yüzyılda, Bowen'ın, Sanders v. Maclean (Bowen, 1883) örneğinde, "Bir kargo denizde taşıyıcının elinde iken fiziksel olarak teslim edilemez durumdadır. $\mathrm{Bu}$ transit ve seyahat döneminde, konişmento evrensel olarak taşınan kargonun sembolü olarak kabul edilir ve konişmentoların onaylanması ve teslimi, kargonun sembolik bir teslimi olarak kabul edilir." Konişmentonun malın sahipliliği olarak kullanılması, ticarette konişmento kullanımının en önemli nedenlerinden birisidir. Yurt içi satışların yanı sıra uluslararası satışlarda da tüccarlara malların teslimi. konişmento belgelerinin devri ile sağlanmaktadır (Debattista, 1990). Konişmento devir ve ciro yolu ile el değiştirebilen, malların sahipliliğini gösteren bir belge olarak mal sahibinin taşıma sırasında mallar üzerinde mal sahibi kontrolü sağladığından dolayı, birçok önemli işlevi yerine getirmektedir (Schmitthoff, 2007). Örneğin mallar henüz yoldayken, malların el değiştirmesi/satışı ile ticareti kolaylaştırmaktadır (Debattista, 2009). Özellikle tahıl, maden ve kömür gibi yüklerin taşımacılığında veya petrol tankeri ticaretinde kargo, transit yoldayken genellikle tekrar satışı için pazarlık yapılmakta ve yolda satışı yapılarak, malların sahipliliği, mallar henüz yoldayken birçok kez el değiştirebilmektedir (Williams, 1991). Konişmento alıcıya veya acentesine malların varış limanına varışta fiili teslimatını yapmasını sağlamaktadır. Konişmento mallarının mülkiyeti ile eşdeğerdir ve konişmento malının alıcıya veya bir üçüncü tarafa teslimi (eğer istenirse) malı bu üçüncü kişiye vermede etkili olabilir. Taşınan malın planlanan varış noktasına gelmeden önce nakledilmesi ihtiyac1, ticari borsadaki hızlı yayılma ve artan karmaşık işlemler ile ortaya çıkmıştır (United Nations, 1971). Taşınan malın daha yoldayken, varış noktasına gelmeden el değiştirilebilmesi, ancak konişmentoların devredilebilir olması ile mümkün olabilmektedir.

Konişmento, ayrıca, uluslararası ticarette, taraflarca finansman sağlamak için güvence/teminat olarak da kullanılabilmektedir (Wilson, 2008; Ivamy, 1989). Bankalar, konişmentonun kendi adlarına düzenlenmesini talep ederek, yani konişmento konusu malların sahipliliğini kontrol ederek ihracatçıya finansman sağlayabilmektedir. Özellikle uluslararası satış sözleşmelerini finanse etmek için örneğin akreditifli ödemelerde, bankalar açısından malların sahipliliğinin kontrolü nedeniyle, teminat olarak konişmentoların bankaları adına düzenlenmesi şartı ile akreditif ödemelerinin temelini oluşturmaktadır (Proctor, 1997, Meral, 2018).

Literatürde çok çeşitli şekilde tanımlanmış olmakla birlikte, konişmentonun standart bir tanımı olmayıp, taşımacılığın alıcı ve satıcılar arasındaki maliyet ve yükümlülüklerini karşılayan standart bir nakliye terimi olan Uluslararası Ticaret Odası (ICC, 1990), INCOTERMS 1990 yayınında, "konişmento" terimi, taşıyıcı tarafından veya onun adına verilen, bir konişmento belgesidir ve bir taşıma sözleşmesinin ve gemide bulunan malların teslim edildiğinin kanıtıdır. Nitekim, Uluslararası Ticaret Odası Akreditiflere ilişkin Kurallar UCP 600 sayılı yayınında (International Chamber of Commerce, 600), konişmento kelimesi yerine taşıma belgesi (transport document) olarak bahsedilerek, 'nasıl adlandırılmış olursa olsun' (however named) ibaresiyle, taşıma belgesinde olması gereken özellikler tanımlanmaktadır. Bir konişmento, ön ödemeli olarak ya da varışta ödenebilir olarak ödenebilir" düzenlenebilmektedir.

\section{Konişmentoların Düzenlenmesinde Tabi Olduğu Kurallar}

Konișmento benzeri bir belgenin Roma döneminde de kullanıldığına dair kanıtlar olmasına rağmen, modern konişmentolar, Akdeniz'deki büyük ticari şehirler ile birlikte 11. yüzyılda doğmuştur (McLaughlin, 1925). Gönderilen malların kaydını sağlamak için, ilgili malların taşındığı gemi kayıtlarının kullanımı gayri resmi olarak başlanmış olsa da, kısa sürede -en azından bazı limanlarda- yasal bir temele oturtulmuştur (Bensa, 1925).

\section{Romalılar Dönemi}

Konişmentoya ilişkin ilk yazılı kaynaklar Romalılar dönemine aittir (Karan, 2004). Başlangıçta yük sahipleri veya görevlileri gemiye yüklenen mala refakat etseler dahi, her zaman bu mümkün olmadığı için hatta gemide olsalar dahi mal üzerindeki kontrolü sağlamak için kaptandan yüklenen mallara ilişkin bir belge düzenlenmesi talebiyle, yükün teslim alındığını gösteren makbuz kullanılmaya başlanmıştır. Zaman içinde içerik bilgileri, yüklenen mala ait daha fazla bilgi içeren, daha kolay anlaşılır bir belgeye dönüşmüştür (Çağla, Kender, 2010).

\section{Harter Act}

Tarihte daha önce düzenlemeler olmasına rağmen, göze çarpan ilk önemli düzenleme 1893 yılında ABD'de çıkartılan Harter Act'dır. Yasanın amacı, taşıyan ve taşıtan arasında bozulan menfaat dengesinin tekrar kurulmasını sağlamaktır (Ateş, 2006). Her ne kadar taşıyıcının sorumluluğunu sınırlandırması, bazı şekil şartları ve ispat yükü gibi konuları düzenlemediği için tam anlamıyla başarıya ulaşamamış olsa da içeriği ve konişmento ile ilgili sorunların uluslararası düzenlemeler ile çözüm bulunmasına yönelttiği için tarihte önemli bir yere sahiptir (Kula, 2012).

\section{Lahey-Visby Kuralları}

Lahey Kuralları, Harter Act'in etkilerinin sonucu olarak 1924 yılında, “Konişmentoya Müteallik Bazı Kaidelerin Tevhidi Hakkında Milletlerarası Sözleşme” (Lahey 
Kuralları) kabul edilmiştir. Lahey Kuralları'nın en önemli özellikleri, konişmentonun düzenlenen taşımalara uygulanacak olması, konişmentoyu tarif etmekten kaçınması, ancak buna karşılık düzenlenme şekli ve taşıyanın sorumluluklarını ayrıntılı bir şekilde düzenlemiş olması nedeniyle dünyada kabul gören bir sözleşme olmuştur. Türkiye'de Lahey Kuralları'na taraf olan ülkeler arasındadır. Lahey Kuralları'nın zamanla eskimesi ve günün gereksinimlerini karşılayamaması sonucu Comite Maritime International (CMI) çalışmaları ile 1969 yllında "Konişmentoya Müteallik Bazı Kaidelerin Tevhidi Hakkında 25 Ağustus 1924 tarihli Milletlerarası Brüksel Sözleşmesinde Değişiklik Yapan Protokol" (Visby Protokolü) ortaya çıkmıştır. Visby Protokolü'nde genel olarak çok fazla değişiklik yapılmamış, konişmentoya iliş̧kin birkaç konuda değişikliğe gidilmiştir (Yancey, 1982).

\section{Hamburg Kuralları}

1978'de her ne kadar Lahey Visby Protokolü ile yenilenmiş sayılsa da ihtiyaçlar nedeniyle Lahey-Visby kurallarından tamamen bağımsız, yeni bir düzenlemeye ihtiyaç duyulmuştur. Bu nedenle, "Deniz Yoluyla Eşya Taşınmasına İlişkin Birleşmiş Milletler Konvansiyonu" (Hamburg Kuralları) kabul edilmiştir. Hamburg Kuralları, LaheyVisby Kuralları'nın aksine konişmentolu taşımalarda uygulanması gibi bir sınırlama getirilmemiş, sözleşmenin uygulama alanını genişlemiştir. Hamburg Kuralları, Lahey kurallarına değiştirmek amacıyla değil yerini almak amacı ile hazırlanmışsa da taşıyanın sorumluluğunda temel değişiklikler getiren, daha kapsamlı olsa da Hamburg Kuralları dünyada çok fazla kabul görmemiştir. Türkiye de Hamburg Kuralları'na taraf olmamıştır. Hamburg Kuralları'nın, Lahey-Visby Kuralları'nın yerini tam anlamıyla alamaması, uluslararası kurallarda karışıklığa neden olmasının yanı sıra (Süzel, 2013), gelișen konteynır taşıması, teknolojik gelişmeler ile birlikte elektronik ticaretin yaygınlaşması ve elektronik belge düzenlenmesi ihtiyacı, limandan limana taşımadan, kapıdan kapıya taşımaya geçilmeye başlanması gibi başlıca etkenlerle yeni bir düzenlemeye ihtiyaç duyulmuştur (Wilson, 2008). Birleşmiş Milletler Komisyonunun yeni bir uluslararası düzenleme nedenlerinden birisi de her iki rejimin de çeşitli yönlerden farklılık göstermesidir.

\section{Rotterdam Kurallart}

Yeni düzenleme, 1996 yılında United Nations Commission on International Trade Law (UNCITRAL) ve CMI'nin ortak çalışması başlamıştır. 1996-2001 yılları arasında CMI'nın sektör görüşlerini alarak geniş kabul görmesi amaçlanan taslak metni, 2001'de UNCITRAL'a sunulmuştur. 2002 yılında UNCITRAL'de hükümetler ve sivil toplum kuruluşları ile birlikte taslak metin üzerinde çalışılmaya başlanmıştır. 2008'de Temmuz ayında UNCITRAL komisyonu tarafindan onaylanan metin, 11 Aralık 2008'de de BM Genel Kurul'unda "Tamamen veya Kismen Deniz Yoluyla Uluslararası Eşya Taşınmasına İlişkin Sözleş̧meler Hakkında Birleşmiş Milletler Konvansiyonu" adıla onaylanmıştır. Düzenleme, 20-23 Eylül 2009 tarihlerinde Hollanda/Rotterdam şehrinde imzaya açılmış ve henüz 16 ülke tarafindan onaylanmıştır. Diğer ülkelerin henüz imzalamamış olmasının en önemli nedenlerinden birisi, Rotterdam Kuralları, önceki Hamburg Kuralları vb. nin aksine, kısmen kabul edilebilen bir kurallar dizisi olmayıp, uygulamaya geçildiği anda tüm maddelerinin kabul edilmesi gerekmektedir. Özellikle Madde 18 ile taşıyanın sorumluluğu genişletilerek, sözleşme tahtında direkt veya dolaylı olarak taşıyanın yapması gereken hizmeti üstlenen veya sorumluluklarını yüklenen kişi ya da tarafın yaptıklarından da taşıyıcı sorumlu tutulmaktadır. (Berlingieri, 2009). Bu nedenlerle, UNCITRAL komisyonu tarafindan kabul edilerek, onaya sunulan metin, Birleşmiş Milletler Genel Kurul'unda 2008'de kabul edilmiştir. 2009'da imzaya açılan Rotterdam Kuralları, henüz uygulamaya geçilmesi için gerekli 25 ülke onayına ulaşmamıştır. İmzaya açıldığı yerin ismini almış olup kısaca "Rotterdam Kurallarl" olarak da anılmaktadır (Süzel, 2013). Yeni sözleşmenin amacı, malların deniz yoluyla taşınması konusundaki mevcut kuralları, daha önceki rejimlerde bulunmayan multimodal taşımacılık ve elektronik belgelerle ilgili kuralları da içeren yeni bir rejimle değiştirmektir. Rotterdam Kuralları, elektronik taşıma kayıtlarını düzenleyen maddeler içermektedir (CMI, 2018). 25 ülke onayının tamamlanmasını takiben bir yıl sonra yürürlüğe girmesi halinde, ülkelerin yerel yasal mevzuatının düzenlenmesini kolaylaştıracaktır.

Özetle, şu anda üç farklı uluslararası kurallar dizisi deniz taşımacılığı ile ilgili kuralları düzenlemektedir. 1. Lahey ve Visby Kuralları ağırlıklı olarak tamamen malların sahipliliğini gösteren, devir ve ciro yolu ile devredilebilen konişmentolar ağılıklı iken, 2.Hamburg Kuralları aynı zamanda ciro edilemeyen (non negotiable) konişmentolarını da kapsamaktadır. İki farklı kurallar grubu nedeniyle UNCITRAL tarafından daha geniş kabul gören, standart ortak kurallar için daha geniş kapsamlı, elektronik konşimentoya da ilgi tutan ve multimodal taşımacıllı̆ı da kapsayan Rotterdam Kuralları düzenlenmiştir.

\section{Uygulamada Bankalar Tarafindan Kabul Edilen ICC Kurallart}

Halen geçerli olan farklı uluslararası kurallar dizisi olmakla birlikte, standart bir tanımı olmayan konişmentoyu, Uluslararası Ticaret Odas1, tüm dünyada kabul gören standart kurallarında (ICC, 2007), "bir konişmento, nasıl adlandırılmış olursa olsun" diye tanımlamıştır. İlgili yayında, bir konişmentonun taşıması gereken şartlar ise aşağıdaki şekilde tanımlanmaktadır. Konişmentoların düzenlenmesi kurallarına içeren ICC 600, 20.maddesinde özetle bir konişmento, nasıl adlandırılmış olursa olsun, orijinal/asıl, imzalanmış, yüklendi kaydı, yükleme yeri, boşaltma yeri, taşıma şartlarını belirtmeli ve charter party'ye tabi olduğuna ilişkin hiçbir kayıt olmamalıdır. $\mathrm{Bu}$ doğrultuda;

1- Konişmento Orjinali/Aslı Şartı: Tek asıl (orijinal) konişmento olması gerektiği eğer birden fazla orijinal düzenlenmesi durumunda, kaç adet orijinal düzenlendiğinin konişmento üzerinde belirtilmesi gerektiği ve belirtilen orijinal sayısının (genellikle üç adet orijinal düzenlenmektedir) yani konişmentonun düzenlenen tüm orijinal/asıllarının ibraz edilmesi gerekmektedir.

2-İsim ve İmza Şartı: Taşımacının ismini göstermeli, taşımacı, kaptan veya acenta tarafından imzalanmalıdır. Acenta tarafindan imzalanması halinde ise acentanın kaptan adına $\mathrm{m}$ yoksa taşıyıcı adına $\mathrm{m} ı$ imza attığı mutlaka belirtilmelidir. 
3-Yükleme Tarihi ve Yüklendi Kaydı Şartı (on board): Yükleme limanının isminin yanı sıra, gemi isminin de belirtilmesi gerekmektedir. İsmi belirtilen gemiye yüklendiğini (shipped) matbu kayıtla gösterilmesi durumunda, konișmento tarihi, yükleme tarihi olarak kabul edilmektedir. Matbu kayıt bulunmaması halinde ise mutlaka ayrıca tarih ve yüklendi (on board) notuyla malların yüklendiği gösterilmelidir. Gemi ismi yerinde 'intended vessel' yazıyorsa ayrıca gemi ismi de mutlaka belirtilmelidir.

4-Taşıma Şartları: Konişmento taşıma şartlarını da kapsamalı veya şartları içeren (kısa form veya arkası boş konişmento) gibi taşıma kaynakları şartlarını belirtmelidir.

5-Charter Party Konişmento'nun Kabul Edilmemesi: ICC'nin ilgili yayın konusu, akreditiflerde açıç̧a 'charter party kabul edilebilir' diye belirtilmediği sürece, kabul edilmeyeceğinden, konişmentolarda charter party'ye tabi olduğuna ilişkin hiçbir kayıt/belirti olmamalıdır. Charter party konşimentolar, aksine bir hüküm olmadığı takdirde kabul edilmemektedir. Bunun en önemli nedeni, 'charter party' konşimentoları diğerlerinden ayıran, daha riskli özelliklerinden kaynaklanmaktadır. 'Charter party' konşimentolar birbirinden iki farklı sözleşmeye tabi oldukları için bankalar tarafından kabul edilmemektedir. Taşıyıcı (carrier), ihtiyaç nedeniyle, başka bir gemi sahibinden (shipowner) gemi kiralayabilmektedir. Bu durumda, taşıyıcı kiralayan (charterer) sıfatı ile gemi sahibi arasında gemiyi kiralamak için bir sözleşme yapmaktadır. $\mathrm{Bu}$ sözleşmenin standart bir formatı olmayıp, farklı yasal düzenlemelere sahip olması mümkündür. Gemi sahibinden, gemiyi kiralayan (charterer), malların taşınması için malları gönderen ile malların sözleşmesi için ayrı bir sözleşme yapmaktadır. Ancak gemiyi kiralayan, gemi sahibine ilk sözleşmeden doğan taahhütünü yerine getirmeyerek, örneğin kiraladığı geminin, kira bedelini ödemezse, gemi sahiplerinin, gemideki mallara el koyarak dahi gemi kirasını tahsil etme hakları olduğundan, diğer konşimentolardan farklı olarak, malları gönderen ile kiralayan (charterer) arasındaki 2.sözleşme hakları yani taşınmak üzere yüklenen malların rehin edilme riski-ki navlun bedeli taşıyıcıya peşin ödenmiş dahi olsa-ortaya çıkabileceğinden, bankalar 'charter party' sözleşme kabul etmemektedir. 'Charter party' sözleşmeye izin veren özel bir şart olsa dahi, bankalar sözleşme şartlarını incelemekle yükümlü değillerdir.

6-Aktarma: Aktarma da aksine bir hüküm yoksa kabul edilmeyen bir husus olup, taşımanın tek ve aynı konişmento altında taşınması halinde, aktarma yapılabilir vb. notları içeren konişmentolar kabul edilebilmektedir.

\section{Elektronik Konişmento (BOLERO)}

Konişmentolar, sadece uluslararası ticarette değil, yerel ticarette de yaygın olarak kullanılmaktadır, özellikle taşımacılık endüstrisindeki gelişmeler nedeniyle artık ulaşımın daha hızlı olması nedeniyle yeni ulaşım belgeleri ihtiyacı ortaya çıkmıştır. Belgelerin varış limanına geç varışları, genellikle konişmento kullanımıyla ilişkilendirilmektedir (Proctor, 1997), malların teslimi için orijinal konişmentonun gecikmesi, geminin limanda beklemesi gibi ilave masraflara vb. yol açmaktadır.

Taşıma sisteminde, daha hızlı gemiler, konteynerli işleme ve entegre taşıma sistemlerine sahip multimodal taşıyıcılar gibi teknolojik yenilikler belgelerin standardizasyonuna neden olmuştur (Giermann, 2004). E-konişmento olarak adlandırılan, elektronik konişmento, BOLERO (Bill of Lading Electronic Registration Organisation, 2009) da bu ihtiyaçlar doğrultusunda ortaya çıkmıştır. E-konişmento (BOLERO) 1994 yılında kısmen Avrupa Birliği tarafından finanse edilen bir pilot projedir. 'Bolero.net' Eylül 1999'da başlatılan kağıtsız uluslararası ticaretin yasal yapısıdır. Bolero International Limited tarafindan işletilmektedir. SWIFT (Society for Worldwide Interbank Financial Transactions) ve TT Kulübü (Transport Mutual Insurance Association Limited aracılığıyla) arasında bir ortak girişimdir. Bolero kullanıcılarının sahip olduğu kar amacı gütmeyen bir dernek olan Bolero Association Limited'e hizmet vermektedir (Clift, 1999), (Caplehorn, 1999). Bolero Kuralları (Bolero Rule Book) hem üyelerin kendi aralarındaki hem de üyeler ile Bolero Association Ltd. arasındaki ilişkileri düzenlemektedir (Bolero, 2009). Bolero Association Ltd. yanı sıra, kurulan Bolero International Ltd. ise teknolojik işlemler, üyeler için şifreli mesajlaşma, eşebeke, elektronik konişmento merkezi gibi işlemleri kapsamaktadır. Bunun dışında ise kullanıcılar ve kurumsal kurumların kendi aralarında bağlanabilmeleri için web tabanlı bir ağ olarak bolero.net oluşturulmuştur (Bolero.net, 2009).

\subsection{BOLERO Sistem Süreci}

BOLERO, tarafların birbirleriyle elektronik olarak iletişim kurdukları Ana Mesaj Platformu (CMP-Core Messaging Platform) ve malların sahipliliği ve devri gibi elektronik konişmento verileri kaydının olduğu Bolero Title Registry (Bolero Sicil Kaydı) bölümüdür. Ana Mesaj Platformu (CMP), mesaj trafiğinin yanı sıra, mesajların kaydı, kimlik ve imza kontrolünü yapmaktadır. BOLERO sisteminde bir mesajın sonuç üretebilmesi için Ana Mesaj Platformu tarafından alındı teyidinden itibaren 24 saat içerisinde reddedilmemesi gerekmektedir (Brunner, 2007). Ana Mesaj Platformuna, taşıyıcı tarafından düzenlenen elektronik konişmento, elektronik imza ve referans numarası ekli olarak gönderilen mesaj, Ana Mesaj Platformu tarafından kontrol edilip, kaydedildikten sonra, taşıyana bildirim yapılmaktadır (Karan, 2004). Ancak, sadece taşıyıcı tarafından onaylandiktan sonra elektronik konişmento, Ana Mesaj Platformu tarafindan elektronik veri sicili olan Bolero Title Registry'e gönderilerek, sicil kaydı oluşturulmaktadır (Kaya, 2006). Onaylanarak oluşturulan sicil kaydı, 'Bolero Title Registry' tarafindan yükletene gönderilmekte, yükleten de yine Ana Mesaj Platformu aracılığ alınan konişmentoyu aldığını taşıyana bildirmektedir (Senekal, 2010). Burada yükleten, bu bildirimden itibaren 24 saat içerisinde konişmentoyu kabul etmediğine dair bir bildirimde bulunmaz ise taşıyan ve yükleten arasında konişmento ilişkisi kurulmaktadır (Kubilay, Akıntürk, 2001). Konişmento devir işlemlerinde ise, devreden yine Ana Hesap Platformu aracılığıyla devir talebini devralan ve taşıyana göndermekte, taşıyanın aynı platform üzerinden teyiti sonrası, yeni hamil 24 saat içinde reddetmez ise devredilen konişmento kabul edildi sayılarak, sicilde devir değişikliği yapılmaktadır (Marusic, 2012). Ancak devralan kişinin BOLERO sistemine dahil olmaması halinde ise Bolero Association Ltd. tarafindan geleneksel kâğıt konişmento düzenlenerek, yeni devralan sahibine/hamile teslim edilmektedir (Kaya, 2006). Konişmentonun devri ile BOLERO Elektronik Konişmento Kurallarında tanınmış 
haklar devredilmekte, bunun dışında herhangi bir hakkın devri veya başka bir surette senede hamil olabilme imkânı bulunmamaktadır (Karan, 2004). Konişmento haklarının devri İngiliz Hukuk sistemine göre, atama (attornment) ve yenileme (novation) yöntemi ile gerçekleştirilmektedir (Brunner, 2007). Varış limanında ise yeni hamil üye olmadığı için zorunlu olarak devir için düzenlenen geleneksel kağıt konişmentonun ibrazına gerek kalmaksızın, elektronik sicilde hamil olarak görülmesi yeterli olmaktadır (Senekal, 2010).

\subsection{BOLERO Sistem Avantajlar1}

Bolero sistemde düzenlenen sicil konişmento uygulaması ile kağıt konişmentoya eşlenik bir yapı oluşturulmaya çalışılmıştır. AB finansmanı desteği ile SWIFT, TT Club gibi kurumların da desteği ile kurulan BOLERO sadece elektronik konişmento değil, her türlü elektronik belgenin gönderilmesine olanak sağlayan, bütünleşik, parametrik bir sistem olduğundan, diğer elektronik belgelerin de bu sistem üzerinden gönderilmesi mümkündür (Karan, 2004). İlerde tüm tarafların yer alacağı, mevcut karmaşık uluslararası ticaret ödemelerinin yerine kullanılabilecek sade ancak güvenilir tek bir elektronik uluslararası ticaret belgesinin düzenlenmesini çok yararlı olacaktır (Civelek ve Sözer, 2003). Bu belgenin diğer talep edilen örneği menşei'de istenen bilgileri de kapsaması halinde tek elektronik belge ile elektronik ortamda tüm işlemler gerçekleşebilecektir.

Bolero konişmentosu düzenlenen taşımalarda, taşıma sigortaları, bildirimi yapılması kaydıyla, P\&I Kulüpleri (PI Club, 2019) tarafindan yapılmaktadır. Elektronik ortamda sigortanın da yapılmasına olanak sağlayan bu sistem, sigorta, ödeme, uluslararası satış vb. işlemleri çok kolaylaştıracaktır (Karan, 2004).

Deniz ticaretinde elektronik işlemlerin artmasıyla, taşıyıcı ve mal gönderenlere, sözleşme kolaylığı, uluslararası işlem yapabilme olanağı, ulaşılabilirlik nedeniyle rekabette kalitenin artması, pazarlama giderleri ve bürokrasinin azalması, işlem sürelerinin kısalması, hızlı ve anında iletişim, taşıma ve belge maliyetinin azalması, hızlı ve kolay ödeme gibi sistemin sağladığı çeşitli avantajlar bulunmaktadır (Çağa, Kender, 2009).

\subsection{Bolero Sisteminin Yaygın Kullanımının Önündeki Engeller}

Konişmentoların elektronizasyonu ile ilgili birçok araştırma yapılmasına karşın (BOLERO Final Report, 1995), tüm çabalara karşın sistemin başarılı olduğunu söylemek mümkün değildir (Karan, 2004). Güvenlik gerekçesiyle dahi olsa, dışa kapalı bir sistem olması, herkese açık olmaması yaygınlaşmasını zorlaştırdığı için eleştirilmektedir (Goldby, 2008), (Dubovec, 2006). BOLERO sistemine üyelik şartı ve birçok çeşitli sözleşme ve kurallar dizisine maruz kalmak da istenilen düzeyde kullanılmasının önünde bir engel olmaktadır (Brunner, 2008). Merkezi Sicil Sisteminin (Bolero Association Ltd.) sinırlı sorumluluk tutarı yeterli bulunmamaktadır. Her ne kadar zaman içinde arttırılmış olsa dahi, sektörün güvenini kazanacak istenen düzeye henüz gelmemiştir (Karan, 2004). Bankacıllk sektörünün de desteğini maalesef istenilen düzeyde kazanamamıștır, uygulamanın bu nedenle başarılı olmadığı ileri sürülmüştür (Dubovec, 2006). Ülkelerin hukuki alt yapısı, elektronik konişmento kullanımına uygun olmadığı için kullanımı yaygınlaşmamaktadır.

Elektronik konişmentonun yaygınlaşmasının önündeki en önemli engellerden birisi, bankalar tarafindan uygulamada hala geleneksel orijinal, malların sahipliliğini gösteren kağıt konişmentoların teminata alınarak, taraflara finansman sağlamasıdır. İthalatçının bankasına ancak orijinal kağıt konişmento bedelini ödeyerek, bankasından malları gümrükten çekebilmek için gerekli olan belgeleri teslim alabilmesi mümkün olmaktadır. Bankaların elektronik konişmentoyu, benzer şekilde, orijinal kağıt konişmento gibi teminata alması, finansman sağlaması, gümrükten malların çekilebilmesi için elektronik konişmentonun devrini sağlaması ve en önemlisi ihracatçıya ödemeyi yapabilmesi halinde yaygın olarak kullanılmaya başlayabilecektir. Taraflar hızla elektronik konişmento uygulaması için talepte bulunabileceklerdir. Gümrük işlemlerinin keza elektronik konişmento ile yapılabilmesi için yerel hukuk alt yapısının uygun hale getirilmesi gerekmektedir. D1ş ticaretin yüzde 84'ünün deniz yolu ile yapıldığını göz önünde tutarak, bu uygulamanın biran önce bankalar tarafindan uygulamaya geçilmesi için uluslararası ticaret kuruluşları, ICC, SWIFT, bankalar birlikleri, gümrük müdürlükleri vb. kurumların ortak kabul edecekleri standart kurallar ve yerel hukuki kuralların da bu doğrultuda değiştirilmesi gerekecektir. ICC'nin elektronik ibrazlar ile ilgili kuralları (ICC, 2002) düzenlenmiş olmasına karşın henüz bankalarda elektronik ibraz yaygın değildir.

\section{Sonuç ve Öneriler}

Konişmento, uluslararası deniz ticaretinde yüzyıllardır kullanılan, malların sahipliliğini gösteren, devir ve ciro edilebilir özelliği nedeniyle, aynı zamanda bankalar açısından teminat olarak kullanılabilen, kıymetli bir evraktır. $\mathrm{Bu}$ nedenle uygulamada, elektronik konişmentonun bu özellikleri ile geleneksel orijinal kâğıt konişmentonun yerine geçmesi oldukça zordur. Avrupa Birliği'nin BOLERO projesini desteklemesi, dünya bankacılı//finans kurumlarınca kullanılan SWIFT alt yapısı ile entegre bir sistem olmasına karşın elektronik konişmento (BOLERO)'nun kullanımı maalesef yaygınlaşamamıştır. Oysa elektronik konişmentolar, orijinal konişmentoların varış yerine gecikmeli gelmesinin önlenmesi, maliyetlerin azalması ve elektronik ortamda kaybolma riski olmaksızın, güvenli elektronik ortamda saklanabilmeleri nedeniyle, klasik orijinal kâğıt konşimentolara göre daha avantajlı olabilmektedir. Elektronik konişmento ve e-belgelerin kullanımı ile uluslararası ticaret işlemlerinin maliyeti de düşecektir. Örneğin, Birleşmiş Milletler, Asya ve Pasifik Bölgesi Ekonomik ve Sosyal Komisyonu (ESCAP) raporuna göre, tüm Asya-Pasific bölgesinin ticaret belgelerinin elektronik ortama çevrilmesi için adımlar atılıp, elektronik ticaretin kolaylaştırılması halinde, ihracat için gereken sürenin $\% 44$ azaltılarak, maliyetlerin düşürülmesi ile ihracat tutarının \%31 oranında artarak, 257 milyar dolara kadar çıkması sağlanabilecektir (ESCAP, 2018). Elektronik konişmento ile orijinal konişmentonun gecikmesinden kaynaklanan sorunların önüne geçilebilecektir. Konişmentolar, uluslararası ticaretin temel belgelerinden birisi olup, uluslararası ticaretin finansmanında kullanılan yöntemlerde, bankalar tarafından orijinal konşimento ibrazı karşılığı ödeme yapılabildiğinden, bankaların uluslararası 
kurallardan doğan ibraz süresi ve inceleme süreleri (beş iş günü) içinde belgeleri incelemeleri, taşımacılıkta daha hızlı gemilerin kullanılması vb. nedeniyle, bazen gemi, konşimentodan önce varış yerine ulaşmaktadır. Malların kıymetli evrak olan orijinal deniz konişmentosu -hamili, yükün orijinal konşimento ibrazı karşılığında teslim edilme güvencesi nedeniyle konşimentonun kendisi adına/emrine düzenlenmesi talep etmiştir. Keza taşıyan da konşimento karşılığı malı teslim ederek taahhütlerinden kurtulmaktadır (Van der Ziel, 2004). Bu durumda, gecikme nedeniyle, malların teslim edilmesi için orijinal konşimento ibraz edilemediğinde, konşimentosuz teslim için bankalar tarafindan garanti mektubu düzenlenmesi gerekmektedir. $\mathrm{Bu}$ da maliyeti arttıran bir unsurdur. Öyle ki, 1990'larda yapılan bir araştırmada yaklaşık 420 milyar dolarlık uluslararası ticaretin, yüzde 7'sinde, orijinal konşimento ibraz edilmediği için teminat belgeleri karşılığı malların teslim edildiği belirtilmektedir (Williams, 2010). Bir başka araştırmada, konişmentoların veya yükün teslimi için garanti mektubu düzenleme maliyetinin, taşıma maliyetinin yaklaşık \%15 olarak tahmin edilmektedir, elektronik konişmento kullanılması halinde ise garanti mektubu hazırlanması/teslimi \%90 oranında azalarak, diğer maliyetler düşmektedir. Konişmento teslimi genellikle 20 günlük bir süreye tekabül ederken, e-konişmento kullanılması durumunda teslimat çok daha kısa sürede, "Bolero sistemi" ile 4,5 günde tamamlanmaktadır. Ayrıca elektronik konişmentolar fiziksel olarak elden ele aktarılmadığı için, uzun süre elektronik olarak güvenli bir şekilde saklanabilir ve kâğıt konişmentolar gibi kaybolma riski yoktur. Dolayısıyla, e-konişmentoların, kâğıt konişmentolarda karşılaşılabilecek riskleri azalttığı ve bu risklere karşı normal şartlarda daha güvenli olduğu görülmektedir (Tan, Star, Wu, 2017).

Tüm bunlara rağmen yaygınlaşmamasının en önemli nedenlerinden birisi ise uluslararası ticarette uygulamada, kıymetli evrak (çek, senet, poliçe gibi) olarak devir ve ciro yolu ile el değiştirilebilen, malların sahipliliğinin de devrine olanak sağlayan deniz konşimentosunun, uluslararası ticaretin yüzde 85 'inin de deniz yolu ile taşındığı göz önünde tutularak, elektronik konşimento (BOLERO)'nun yaygın olarak kullanılabilmesi için öncelikle bankalar tarafından kabul görmesi gerekmektedir. Akreditifli ödemelerde ikincil teminat olarak malların sahipliliğinin kontrolünü elinde tutmak için deniz konişmentolarının banka adına düzenlenmesini talep eden bankaların, elektronik konişmentoları da teminata almaları hatta elektronik konişmentoları öncelikli talep etmeleri halinde, çok uzun süredir, kıymetli evrak olarak alışıla gelmiş uygulamanın elektronik ortama aktarılması hızlandırılabilecektir.

Sadece ithalatçı, ihracatçı, bankalar, taşıyıcılar, sigorta şirketlerinin kabul etmesi yetmeyip, ilgili kuralların, öncelikle yerel yasal düzenlemenin de ülkelerce yapılması gerekmektedir. Uluslararası kuruluşlar, standart, uygulamada kolaylık sağlayan bu tip uygulamaların yaygınlaşması için çaba göstermektedir. Elektronik konşimentoya ilgi tutan ilk uluslararası kurallar dizisi olan Rotterdam Kurallarının henüz uygulamaya geçmemiş olması, elektronik konișmentonun yaygın kullanılmamasının nedenlerinden birisidir. Yerel yasal düzenlemelerin de Rotterdam Kurallarının kabulünü takiben yapılacağı ve teknik alt yapıların da bu doğrultuda yapılması halinde elektronik konişmentonun kullanımının artacağ düşünülmektedir. Ancak yüzyıllık alışkanlıkların, alışılagelmiş uygulamaların, alınan tüm önlemlere rağmen yaşanan sahte konişmento vb. sorunlar yaşayan tarafların elektronik konişmentoya güven duymalarının zaman alacağı göz önünde tutularak, güvenilir bir alt yapı için gereken yatırımlar çok pahalı olduğundan, projenin finansmanında sadece $\mathrm{AB}$ değil, tüm tarafların katkıda bulunmaları, yaygınlaştırılması için tüm tarafların, bankalar dahil, sistemsel düzenlemeleri yaparak, bankaların ödeme sistemlerinde, elektronik konişmentoyu kullanmaları ile birlikte zaman içinde yaygın kullanımı sağlanabilecektir.

\section{Kaynakça}

Astle, W. E. (1983). Legal Developments in Maritime Commerce: Matters of General Interest and Importance Arising Out of Selected Legal Issues. Fairplay Publications.

Ateş, E. (2006). “1924 Brüksel (La Haye) Sözleşmesinin Türk Hukukuna Etkisi”, İstanbul Üniversitesi, Sosyal Bilimler Enstitüsü, Kamu Hukuku Anabilim Dalı, Yüksek Lisans Tezi, İstanbul.

Bennett, W. P. (1914). The history and present position of the bill of lading as a document of title to goods (Vol. 58). CUP Archive.

Bensa, E. (1925). The early history of bills of lading. Genoa: Stabilimento d'Arti Grafiche.

Berlingieri, F. (2009). A comparative analysis of the HagueVisby Rules, the Hamburg Rules and the Rotterdam Rules. UNCITRAL Working Groups Document, 1, 2-25.

Bolero Association. (2009). Electronic Bills of Lading (eBL). (Erişim: 10/05/2019), http://www.bolero.net/home/electronic-bills-lading/

Bolero Association. (2017) Digitisation will help delete the fraudsters from the trade finance system (Erişim: 10/05/2019), http://www.bolero.net/digitisation-willhelp-delete-the-fraudsters-from-the-trade-financesystem/

BOLERO Final Report. (1995). TEDIS programme of the European Commission.

Bowen, L. J. (1883). Sanders v. Maclean.

Brunner, R. (2007). Electronic transport documents and shipping practice not yet a married couple, L.L.M. Shipping Law Thesis, Zürich, Switzerland.

Caplehorn, R. (1999). Bolero. net-The Global Electronic Commerce Solution for International Trade. Butterworths Journal of International Banking and Financial Law, 14(10), 421-424.

Civelek, M. E., and Sözer, E. G. (2003). İnternet Ticareti Yeni Ekososyal Sistem ve Ticaret Noktaları. ISTANBUL: BETA YAYINLARI.

Clift, J. (1999). Electronic Commerce: The UNCITRAL Model Law and Electronic Equivalents to Traditional Bills of Lading. Int'l Bus. Law., 27, 311.

Comitime Maritime International. (2018). Rotterdam Rules and E Commerce, (Erişim 13.08.2019). 
(https://uncitral.un.org/sites/uncitral.un.org/files/mediadocuments/EN/Colloquia/rotterdam_rules_and_ecommerce_-_may_2018.pdf)

Çağa, T., \& Kender, R. (2009). Deniz ticareti hukuku: Giriş, gemi, donatan ve kaptan. XII Levha.

Debattista, C. (1990). Sale of goods carried by sea. Lexis Law Publishing (Va).

Debattista, C. (2008). Bills of lading in export trade. Tottel Publishing.

Deniz Ticaret Odası. (2017). 'Rakamlarla Denizcilik Sektörü ve İstatistikler'. (Erişim: 10/05/2019), http://www.denizticaretodasi.org.tr/Shared\%20Docume nts/Deniz\%20Ticareti\%20Dergisi/subat_ek_2017.pdf)

Dubovec, M. (2005). The problems and possibilities for using electronic bills of lading as collateral. Ariz. J. Int'1 \& Comp. L., 23, 437.

Economic and Social Commission for Asia and the Pacific ESCAP. (2018). Trade Facilitation and Paperless Trade Implementation in CAREC Countries, (Erişim: 13.08.2019 https://www.unescap.org/resources/tradefacilitation-and-paperless-trade-implementation-careccountries)

Giermann, H. (2004). The Evidentiary Value of Bills of Lading and Estoppel, LIT Verlag, Muenster.

Goldby, M. (2008). "Electronic Bills of Lading and Central Registries: What is Holding Back Progress?", Information \& Communications Technology Law, Vol. 17, No.2, June 2008.

ICC. (2002). eUCP-The Supplement to the Uniform Customs and Practice for Documentary Credits for Electronic Presentation. ICC. (1990). International Chamber of Commerce. Incoterms, 1990. ICC Publishing.

International Chamber of Commerce. (2006). ICC Uniform Customs and Practice for Documentary Credits, 2007 revision. Paris, France: ICC Services Publications Department.

Ivamy, E. R. H., and Payne, W. (1989). Payne and Ivamy's carriage of goods by sea. Lexis Pub.

Karan, H. (2004). Elektronik Konişmento, Turhan Kitabevi.

Kaya, M. (2006). Elektronik Veri Değişiminin Özel Bir Uygulaması Olarak Elektronik Konişmento, Yeditepe Üniversitesi, Sosyal Bilimler Enstitüsü, Hukuk Yüksek Lisans1, İstanbul.

Kindred, H. M. (1988). Modern methods of processing overseas trade. J. World Trade, 22, 5.

Kozolchyk, B. (1992). Evolution and present state of the Ocean Bill of Lading from a Banking Law Perspective. J. Mar. L. \& Com., 23, 161.

Kubilay, H. ve Akıntürk, E. (2001). Elektronik Konişmento, Prof. Dr. Hayri Domaniç'e 80. Yaş Günü Armağanı, C. I, Beta, İstanbul.

Kula Değirmenci, N. (2012). Çoklu Taşıma İşleticisi Olarak Taşıma İşleri Komisyoncusunun Sorumluluklarına ve
Sorumluluk Sigortası Himayesine İlișkin Bir İnceleme. Dokuz Eylül Yayınları

Marusic, M. (2012). A Gateway to Electronic Transport Documentation in International Trade: The Rotterdam Rules in Perspective, Lund University, Faculty of Law, Maritime Law, Master Thesis.

McLaughlin, C. B. (1926). The evolution of the ocean bill of lading. The Yale law journal, 35(5), 548-570.

Meral, Y. (2018). Documentary Risk in International Trade. In Strategic Design and Innovative Thinking in Business Operations (pp. 413-431). Springer, Cham.

Mo, J. (2015). International commercial law (Sixth edition). LexisNexis Butterworths, Chatswood NSW

Murray, C.et al. (2007). Schmitthoff's export trade: the law and practice of international trade (Vol. 11). London: Sweet \& Maxwell.

P and I Clubs. (2019). P\&I clubs provides Protection and Indemnity insurance in respect of third party liabilities and expenses arising from owning ships or operating ships as principals. (Erişim: 10/05/2019), https://www.ukpandi.com/about-us/

Proctor, C. (1996). The legal role of the bill of lading, sea waybill and multimodal transport document in financing international sales contracts (Doctoral dissertation).

Sassoon, D. (1995). C.I.F. and F.O.B. Contracts, 4th ed., Sweet \& Maxwell, London.

Senekal, J.H. (2010). The Electronic Bill of Lading a Legal Perspective, Dissertation Submitted in Partial Fulfillment of the Requirements of the Degree Magister Legum in Import and Export Law at the North -West University.

Society for Worldwide Interbank Financial Transactions. (2019). History. (Erişim: 10/05/2019), https://www.swift.com/

Süzel, C. (2013). “Deniz Ticareti Hukukunda Taşıtan ve Yükleten Kavramları: Hakları, Borçları ve Sorumlulukları", İstanbul Bilgi Üniversitesi, Sosyal Bilimler Enstitüsü, Doktora Tezi, İstanbul.

Tan, Star, Wu. (2017). Legal Briefing, Sharing the Club's legal expertise and experience. Electronic Bills of Lading. (Erişim: 13.08.2019). https://www.ukpandi.com/fileadmin/uploads/ukpi/Documents/2017/Legal_Briefing_e_bill_of_Lading_ WEB.pdf

Thomsen, H. B., \& Wheble, B. S. (1989). Trading with EDI: The legal issues. IBC Financial Books.

TT Club (2019) Cover for global transport and logistics, (Erişim: 10/05/2019), www.ttclub.com

Van Der Ziel, G. (2008). Chapter 10 of the Rotterdam rules: control of goods in transit. Tex. Int'l LJ, 44, 375.

United Nations Conference on Trade and Development Secretariat. (1971). Bills of lading;. New York: United Nations

Williams, S. M. (1991). Something old, something new: The bill of lading, in the days of EDI. Transnational Law and Contemporary Problems, 1(2), 555. 
Williams, R. (2010). The Rotterdam Rules: Winners and Losers / Richard Williams. Journal of International Maritime Law, $191-209$.
Wilson, J. F. (2008). Carriage of goods by sea. Pearson Education.

Yancey, B. W. (1982). Carriage of Goods: Hague, Cogsa, Visby, and Hamburg. Tul. L. Rev., 57, 1238. 